\title{
JAK2 NM_004972.3:C.2792A>G
}

National Cancer Institute

\section{Source}

National Cancer Institute. AK2 NM 004972.3:C.2792A>G. NCI Thesaurus. Code

C105911.

A nucleotide substitution at position 2792 of the coding sequence of the JAK2 gene where adenine has been mutated to guanine. 